\title{
PERANCANGAN KUNCI PINTU MENGGUNAKAN NFC RING DAN PASSWORD LOGGER BERBASIS ARDUINO MEGA 2560
}

\author{
Zulhelmi ${ }^{1}$, Reza Nandika ${ }^{2}$ \\ Program Studi Teknik Elektro \\ Universitas Riau Kepulauan Batam \\ Zulhelmi.julee@gmail.com², rezanandikameng@gmail.com²
}

\begin{abstract}
Abstrak
Keamanan merupakan sesuatu hal yang sangat penting terutama bagi mereka yang memiliki barang-barang atau benda yang berharga. Terkadang kunci gembok atau kunci biasa belum cukup untuk melindungi dari bahaya pencurian. Oleh karena itu perlunya suatu sistem keamanan selain kunci dari pencurian. Kunci tersebut dapat diimplementasikan pada NFC Ring sebagai kunci kedua pada pintu sehingga sulit untuk dibuka secara paksa. Pada pintu akan terbuka atau terkunci dengan motor servo. kunci menggunakan contactless perangkat NFC ring yang berdekatan pada NFC Reader, maka secara otomatis sistem yang terpasang pada kunci pintu akan meminta password dan kemudian password tersebut dimasukkan oleh user melalui keypad, apabila password yang dimasukkan benar, maka motor akan menggerakkan kunci pintu sehingga kunci pintu dalam keadaan terbuka/tidak terkunci. Pengujian NFC Ring dilakukan pada 2 jenis NFC ring yang berbeda UID yaitu $N F C$ ring $R 3 F$ dan NFC ring $R 3$ beserta NFC card agar dapat mengenali UID NFC dapat dilihat pada serial monitor yang terdeteksi oleh NFC raeder dengan melakukan scan terhadap NFC reader. Dari hasil pengujian $N F C$ ring seri $R 3 F, R 3$, dan NFC card masing-masing memiliki UID yang berbeda dan juga perancangan alat penelitian menggunakan data logger yang memiliki modul SD dan RTC (real-time clock) sebagai modul penyimpanan untuk menyimpan data seperti data log, membuat jam, cap waktu dan timer alarm, dll., Untuk bahwa pengguna dapat melihat semua kegiatan yang dilakukan saat membuka pintu pengguna atau bagian yang tidak diketahui untuk membuka gembok pintu.
\end{abstract}

Kata kunci : NFC Ring, NFC Reader, Logger shield, kunci pintu

\section{PENDAHULUAN}

Perkembangan dunia komunikasi saat ini sangat baik dan maju. Hal ini ditunjukkan melalui banyaknya sistem komunikasi. Bahkan komunikasi saat ini tidak hanya di gunakan sebagai alat untuk berkomunikasi atau bertukar informasi, namun juga sebagai media untuk mengendalikan sesuatu. Sistem komunikasi peer to peer seperti NFC (Near Field Communication) merupakan teknologi komunikasi yang sedang berkembang. NFC dapat mengirim suatu informasi dengan cepat dan praktis [1]. Namun, karena cepat dan begitu praktisnya, sistem komunikasi ini sangat mudah untuk terkena Man-in the Middle attack, Data Corruption and Manipulation dan serangan lainnya yang dapat merugikan pengguna dari NFC [2]. Dalam suatu jurnal menyatakan bahwa perlu adanya suatu saluran keamanan untuk mengisolasi komunikasi antar perangkat saat melakukan pengiriman data, ini dilakukan untuk mencegah terjadinya Data Corruption and
Manipulation. Dalam jurnal tersebut menyebutkan bahwa solusi dari keamanan pada NFC yang menggunakan 3DES (Data Encryption Standard) atau AES (Advanced Encryption Standard) sebagai saluran keamanan [2].

Keamanan NFC memiliki tingkat keamanan yang baik, sehingga digunakan sebagai kunci dalam suatu sistem. Banyak yang menggunakan NFC sebagai kunci untuk membuka pintu dengan mendekatkan perangkat NFC (NFC Tag, smartphone, NFC Ring atau NFC Card) ke NFC Reader, kunci dari pintu akan terbuka. Tetapi dalam sistem ini memiliki kelemahan yang sama dengan kunci mekanik pada umumnya, jika ada orang lain yang dapat kunci tersebut maka orang lain dapat membukanya. Dari hal tersebut maka akan mengembangkan penelitian dengan sistem kunci pintu dengan NFC ring serta menambahkan password sebagai keamanan kedua saat selesai melakukan autentikasi perangkat NFC ring maka otomatis alat 
perancangan akan meminta password untuk di input ke perancangn alat jika perangkat NFC ring terdaftar dalam NFC reader dan kunci pintu akan terbuka dengan menambahkan keamanan menggunakan password [3].

Sejak dikembangkan tahun 2008, NFC telah diadopsi secara global terutama di Negara - Negara maju. Sampai saat ini NFC telah diuji coba dan komersial pada lebih dari 200 proyek di 54 negara, Contohnya di Amerika, Eropa, Rusia dan Australia teknologi ini telah digunakan secara luas. NTT DoCoMo jepang berencana meluncurkan roaming NFC di kedua Negara dengan program roaming tersebut layanan kupon dan pembayaran dengan NFC yang dimiliki KT digunakan di Jepang dan sebaliknya. Sedangkan di Indonesia NFC sedang di kembangkan sebagai transaksi pembayaran tetapi, Banyak produsen smartphone telah memasang NFC pada produknya antara lain Blackberry, Samsung, Nokia, HTC, LG, Motorolla, dan tentu masih baanyak lagi. Indonesia termasuk terbilang terlambat mengadopsi teknologi NFC, sejauh ini belum muncul laporan internasional sebagai negara pengguna NFC namun tanpa kita sadari teknologi ini sudah mulai banyak digunakan misalnya e-passport [4].

\section{LANDASAN TEORI}

Peninjauan yang ditulis dalam laporan perancangan yang dibuat ini berdasarkan teori yang di dapat dan menjelaskan secara umum dan khusus tentang NFC ring, NFC reader, Arduino mega 2560 dan Motor Servo dan Data Logger. Komunikasi saat ini tidak hanya digunakan sebagai untuk berkomunikasi atau bertukar informasi, namun juga sebagai media untuk mengendalikan sesuatu. Sistem komunikasi peer to peer seperti NFC (Near Field Communication) merupakan teknologi komunikasi yang sedang berkembang. NFC dapat mengirim suatu informasi dengan cepat dan praktis [2]. NFC Ring di sini berfungsi sebagai alat pertama kunci untuk membuka kunci pintu dan password logger sebagai keamanan ke dua untuk membuka kunci pintu. Terdapat pula autentikasi perangkat NFC ring secara otomatis alat perancangan akan meminta password untuk di input ke perancangn alat jika perangkat NFC ring terdaftar dalam NFC reader dan kunci pintu akan terbuka dengan menambahkan keamanan menggunakan password [3]. NFC Reader di sini sebagai alat yang mendaftarkan data dari NFC Ring agar terinput dalam NFC Reader yang menujukkan $I D$

Pertama kunci pintu sebelum menekan keypad pada password logger untuk melakukan pengamanan ke dua pada kunci pintu. Dalam pengiriman data dan perintah yang di lakukan dalam proses data dapat di lakukan salah satu Mikrokontroller yang telah berkembang seperti Arduino mega 2560 yang memberi perintah kepada semua pengoperasian.

\section{A. Pengertian NFC}

NFC(Near Field Communication) adalah Komunikasi jarak-dekat merupakan bentuk komunikasi nirkabel jarak-pendek di mana antena yang digunakan lebih pendek daripada gelombang sinyal operator yang mencegah interferensi gelombang dari antena yang sama [3]. Pada jarak-dekat tidak ada secara garis besar berapa panjang gelombang jarak-pendek namun untuk tujuan praktikal anggap saja panjang gelombangnya seperempat dari gelombang biasa antena dapat menghasilkan medan elektrik, atau medan magnetik, namun tidak medan elektromagnetik. Komunikasi NFC merupakan Medan eletrik yang termodulasi, atau medan magnetik termodulasi, namun tidak berasal dari gelombang elektromagnetik radio. Sebagai contoh, antena putaran kecil juga dikenal sebagai putaran magnetis menghasilkan medan magnet, yang dapat diambil oleh antena putar kecil lainnya, jika cukup dekat [3].

\section{B. Prinsip Kerja dan Transmisi Data NFC}

Teknologi NFC yang memiliki komunikasi yang terjadi memang menggunakan NFC tetapi pengiriman datanya dilakukan dengan teknologi yang berbeda seperti WI - Fi atau Bluetooth. 


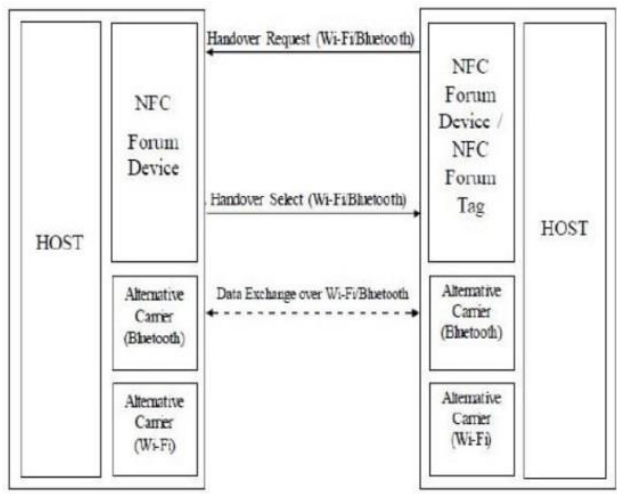

Gambar 1. NFC Handover [3]

NFC yang menggunakan Bluetooth sebagai pengiriman data menggunakan power yang sedikit dan tidak membutuhkan pairing tetapi data yang ditransfer hanyalah (424 $\mathrm{Kbit} / \mathrm{s})$ ini lebih sedikit dibanding dengan menggunakan Bluetooth V2.1 (2.1 Mbit/s)[3].

NFC menggunakan teknik coupling induktif sebanding dengan prinsip transformator yaitu magnetik NFC dari dua kumparan konduktor digunakan untuk memasangkan inisiator (Polling) perangkat dan sasaran (Listener) perangkat. Dalam melakukan pairing kumparan inisiator dan sasaran, pasif perangkat listening juga mempengaruhi perangkat polling yang aktif. Sebuah variasi dalam impedansi dari listening hasil perangkat dalam amplitudo atau perubahan tegangan antena polling perangkat, terdeteksi oleh perangkat polling.
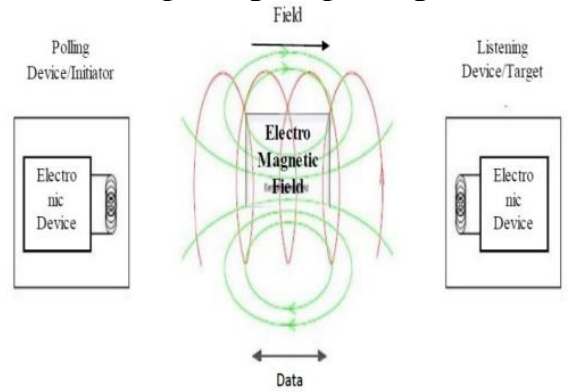

Gambar 2. NFC Transmission [3]

\section{NFC Shied Arduino / NFC Reader}

NFC Shield memiliki modul pemancar PN532 yang terintegrasi yang menangani komunikasi contactless di $13.56 \mathrm{MHz}$ [6]. Shield ini dapat membaca dan menulis, shield ini menerapkan titik ke titik pertukaran data dengan NFC Shield dan NFC Ring. Dalam versi baru ini, ditetapkan $\mathrm{PCB}$ independen yang dapat dengan mudah meregang keluar dari setiap celah yang digunakan, meninggalkan lebih banyak ruang untuk merancang eksterior proyek [6].

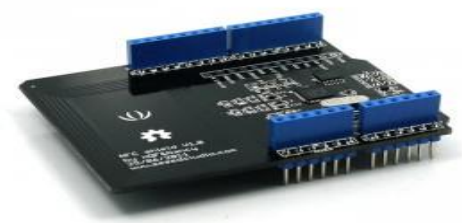

Gambar 3. NFC Shield PN532 [6]

Adapun fitur yang terdapat pada shield ini adalah sebagai berikut:

1. Input Voltage : $5 \mathrm{~V}$

2. Typical Current : $100 \mathrm{~mA}$

3. $5 \mathrm{~cm}$ max effective range

4. SPI pin saving interface

5. Serve for contactless communication at $13.56 \mathrm{MHz}$

6. Support $P 2 P$ communication

7. Support ISI 14443 Type A and Type B protocols

\section{NFC Ring Jakcom R3F Smart Ring}

NFC Ring ini adalah Jakcom R3F sebagai komponen elektronik pintar yang dapat di pakai untuk menghubungkan IC / ID / NFC Card Reader sebagai pengunci seperti ponsel yang mempunyai aplikasi NFC, bagi beberapa informasi atau mengoperasian tergantung fungsi tertentu. Dalam dunia kesehatan modul efektif bisa meningkatkan kinerja manusia dalam bentuk produk dirancang menurut elemen populer internasional, yang diciptakan oleh titanium murni medis, tidak perlu biaya, tinggi tahan air, dan cocok untuk setiap orang setiap saat.

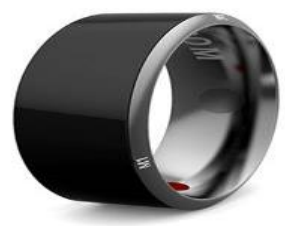

Gambar 4. NFC Ring Jakcom R3F Smart Ring [7].

Spesifikasi model Jakcom R3F Smart Ring yaitu:

Model : Jakcom R3F Smart

Ring

Frekuensi $\quad: 13.56 \mathrm{MHz}$

Jarak yang di hasilkan $: 1.5 \mathrm{~cm}$

Kerja temperature $\quad:-50 \sim+80^{\circ} \mathrm{C}$ 


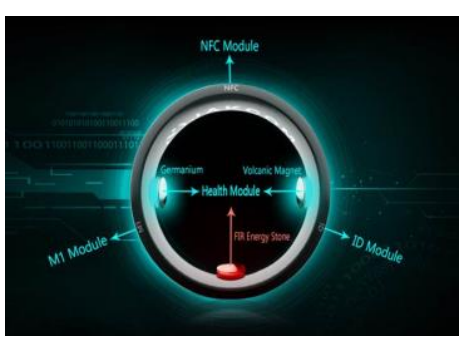

Gambar 5. Struktur NFC Ring Jakcom R3F Smart Ring [7]

\section{E. Arduino mega 2560}

Arduino mega 2560 adalah sebuah board arduino yang menggunakan ic mikrokontroller mega 2560 yang memiliki 54 digital input/output (15 buah di antaranya dapat di gunakan sabagai output Pulse Width Modullusion (PWM),16 buah analog input, 4 UART (Universal asyncrhronous receiver / transmitter), osilator crystal $16 \mathrm{Mhz}$, koneksi USB, jack power, soket ICSP (In-Circuit System Programming) dan tombol reset. Spesifikasinya dapat di lihat pada gambar $2.8[8]$

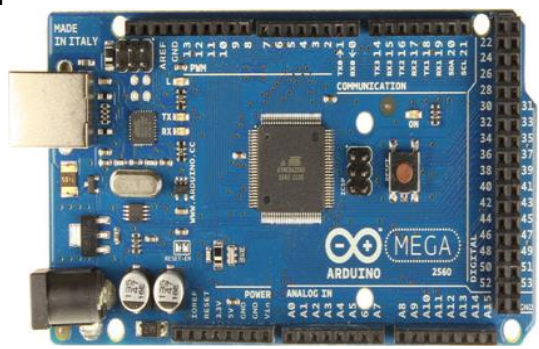

Gambar 6. Arduino mega 2560 [8]

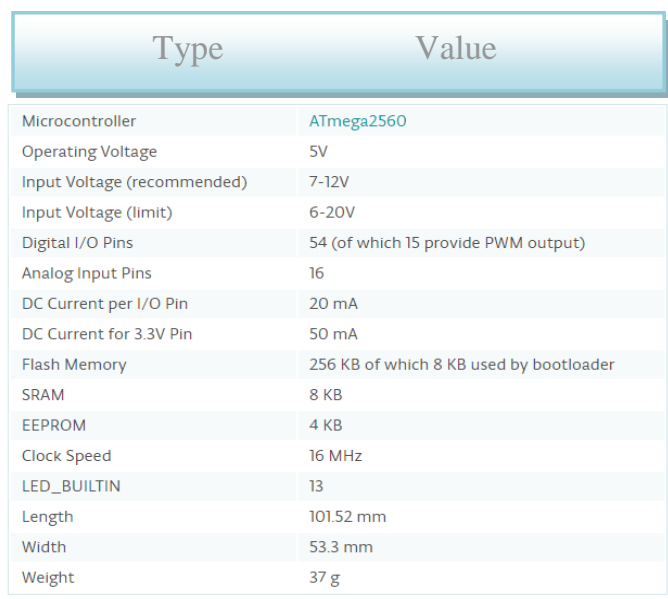

Gambar 7. Spesifikasi Arduino mega $2560[8]$

\section{F. Motor Servo}

Motor servo adalah sebuah motor dengan sistem umpan balik tertutup di mana posisirotornya akan di informasikan kembali kerangkaian control yang ada didalam motor servo. Motor ini terdiri dari sebuah motor DC, serangkaian gear, potensiometer dan rangkaian control.Potensiometer untuk menentukan batas sudut dari putaran servo,sedangkan sudut dari sumbu motor servo diukur berdasarkan lebar pulsa yang dikirim melalui kaki sinyal dari kabel motor[9].

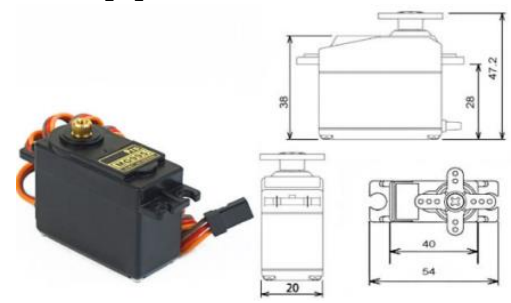

Gambar 8. Motor Servo Tower MG996 [10].

\section{G. Data Logger Shield}

Data Logging Shield adalah perisai yang dirancang untuk murah tapi canggih untuk sebagian besar Tabel Arduino. SD modul dan RTC (real time clock) membentuk satu gabungan Melindungi data logging. SD Card digunakan sebagai modul penyimpanan untuk menyimpan data seperti gambar, dokumen dan catatan dan juga Menyimpan file data pada kartu SD dengan FAT16 atau format FAT32. RTC termasuk memungkinkan proyek mikrokontroler Anda untuk melacak waktu bahkan jika memprogram, atau jika daya hilang. Sempurna untuk merekam data, menciptakan jam, cap waktu, dan timer alarm, dll DS1307 adalah yang paling populer RTC dan bekerja terbaik dengan chip $5 \mathrm{~V}$, seperti Arduino. Juga termasuk dalam perisai ini $3 \mathrm{~V}$ lithium sel untuk RTC [10].

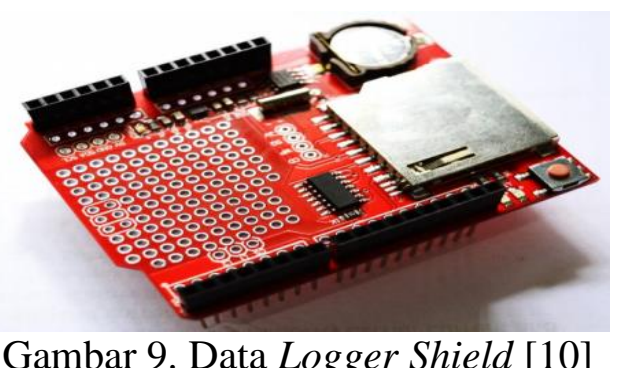

fitur yang terdapat pada data logger shield adalah sebagai berikut:

1. SD card bekerja kartu anta rmuka dengan FAT16 atau format FAT32. Tingkat pergeseran sirkuit $3.3 \mathrm{v}$ mencegah kerusakan pada kartu SD 
2. The real-time clock (RTC) terus waktu bahkan ketika Arduino terputus. Baterai backup dapat bertahan sangat lama.

3. Daerah prototyping untuk konektor solder, sirkuit atau sensor.

4. LED dikonfigurasi (L1 dan L2)

5. Regulator tegangan $3.3 \mathrm{~V}$ terintegrasi adalah referensi yang handal dan juga dapat percaya menjalankan kartu SD yang membutuhkan banyak kekuatan untuk menjalankannya [10].

\section{H. LCD 16X2 (Liquid Crystal Displayd)}

LCD (Liquid Crystal Display) adalah suatu jenis media tampil yang menggunakan kristal cair sebagai penampil utama. LCD sudah digunakan diberbagai bidang misalnya alal-alat elektronik seperti televisi, kalkulator, atau pun layar komputer. Pada postingan aplikasi LCD yang dugunakan ialah LCD dot matrik dengan jumlah karakter $16 \times 2$. LCD sangat berfungsi sebagai penampil yang nantinya akan digunakan untuk menampilkan status kerja alat. Fitur LCD 16 x 2, Adapun fitur yang disajikan dalam LCD ini adalah:

1. Terdiri dari 16 karakter dan 2 baris.

2. Mempunyai 192 karakter tersimpan.

3. Terdapat karakter generator terprogram.

4. Dapat di alamati dengan mode 4-bit dan 8-bit.

5. Dilengkapi dengan back light.

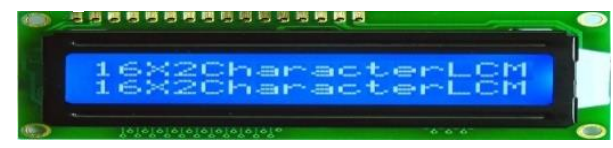

Gambar 10. Bentuk Fisik LCD 16 x 2[11].

Spesifikasi kaki yang terdapat dari LCD 16 × 2 sebagai berikut:

Pin 1 : Ground

Pin 2 : Vcc

Pin 3 : Pengatur kontras

Pin 4 : RS Instruction/Register Select

Pin $5:$ R/W Read/Write LCD Registers

Pin 6 : EN Enable

Pin 7-14 : Data I/O Pins

Pin $15:$ Vcc

Pin 16 : Ground
Cara Kerja LCD Secara Umum Pada aplikasi umumnya RW diberi logika rendah "0". Bus data terdiri dari 4-bit atau 8-bit. Jika jalur data 4-bit maka yang digunakan ialah DB4 sampai dengan DB7. Sebagaimana terlihat pada table diskripsi, interface LCD merupakan sebuah parallel bus, dimana hal ini sangat memudahkan dan sangat cepat dalam pembacaan dan penulisan data dari atau ke LCD. Kode ASCII yang ditampilkan sepanjang 8-bit dikirim ke LCD secara 4-bit atau 8 bit pada satu waktu. Jika mode 4-bit yang digunakan, maka 2 nibble data dikirim untuk membuat sepenuhnya 8-bit (pertama dikirim 4-bit MSB lalu 4-bit LSB dengan pulsa clock EN setiap nibblenya). Jalur kontrol EN digunakan untuk memberitahu LCD bahwa mikrokontroller mengirimkan data ke LCD. Untuk mengirim data ke LCD program harus menset EN ke kondisi high "1" dan kemudian menset dua jalur kontrol lainnya (RS dan R/W) atau juga mengirimkan data ke jalur data bus.

\section{Metode Penelitian}

\section{A. Alir Penelitian}

Alir penelitian pada perancangan alat dapat dilihat pada gambar 3.1 dibawah ini:

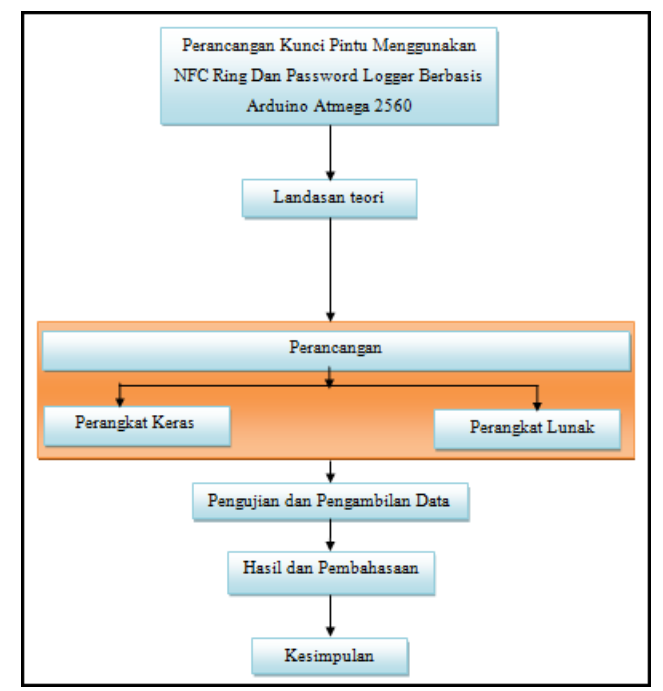

Gambar 11. Diagram Alir Metode Penelitian

\section{Perancangan Sistem}

Dalam perancangan sistem berisi tentang pembuatan mekanik sebagai prototype kunci pintu yang akan dirancang untuk membuka kunci pintu dan dilakukan pengujian mekanik pintu terhadap motor servo agar kunci pintu 
P ISSN 2614-5979

dapat terbuka dalam perancangan system sebagai berikut:

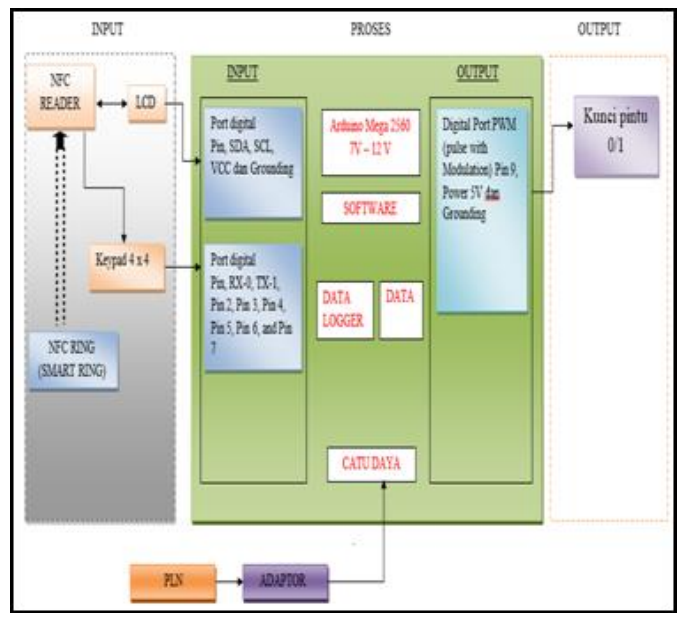

Gambar 12 Diagram Perancangan sistem.

\section{E. Rancangan Perangkat Keras}

Dalam perancangan alat ini, menggunakan perangkat keras agar sistem ini dapat berjalan dengan baik. Dalam sistem ini menggunakan arduino mega 2560 sebagai otak atau perangkat untuk memproses dari jalannya sistem ini. Arduino mega 2560 digunakan untuk memproses data yang masuk dari NFC Reader, data tersebut berupa password serta nama dari perangkat yang mengirimnya, data yang didapat harus sesuai dengan yang ada pada arduino agar dapat menggerakkan motor servo sehingga saat data ID yang di berikan oleh NFC Ring sesuai kepada NFC reader dan diproses oleh arduino dengan baik maka motor servo akan bergerak untuk membuka kunci dari pintu tersebut.

Gambar 13. Rancangan Perangkat Keras

\begin{tabular}{|c|c|c|c|}
\hline NFCRNG & $\begin{array}{l}\text { NFC } \\
\text { READER }\end{array}$ & $\begin{array}{l}\text { ARDUNNO } \\
\text { MEGA } 2560\end{array}$ & $\begin{array}{l}\text { NNOTOR } \\
\text { SERVO }\end{array}$ \\
\hline $\begin{array}{l}\text { Gelombang } \\
13.56 \mathrm{Ahz}\end{array}$ & $\begin{array}{l}\text { ICPN } 532 \\
\text { Signal ISO } \\
14443 \mathrm{~A}\end{array}$ & $\begin{array}{l}\text { Signal Masukan } \\
\text { I/O }\end{array}$ & $\begin{array}{l}\text { Digital } \\
\text { PWM }\end{array}$ \\
\hline
\end{tabular}

(Hardware)

\section{F. Rancangan Perangkat Lunak (Software)}

Peran perangkat lunak dalam prototype ini sebagai pengirim data dan penerima data serta sebagai penggerak dari motor servo. Perangkat lunak memiliki kesamaan dengan perangkat keras yang mengatur proses kerja suatu system. Awal dari sistem ini, perangkat menunggu ditekannya keypad sesuai dengan yang tertera pada gambar diatas. Jika keypad 'A' ditekan maka akan melaksanakan proses login atau buka kunci, jika keypad 'B' ditekan maka akan melaksanakan proses daftar user baru, jika keypad ' $\mathrm{C}$ ' ditekan maka akan melaksanakan proses ubah password sesuai pengguna NFC Ring.

Setelah masuk ke proses login, akan meminta pengguna untuk melakukan scan perangkat NFC Ring. Kemudian jika perangkat NFC Ring tidak dikenal maka akan kembali ke proses awal atau "Start", tetapi jika dikenal maka sistem akan meminta password, password dimasukkan dengan menekan keypad. Jika password benar maka kunci akan terbuka dan kembali ke proses awal.

Proses daftar user baru memerlukan id atau NFC dari admin, jika bukan admin maka tidak bisa melakukan proses pendaftaran user baru. Jika NFC admin dan password admin sudah sesuai maka sistem akan meminta scan NFC Ring untuk pengguna yang baru. Saat proses scan sistem akan memastikan tidak ada 2 user NFC Ring dengan ID yang sama. Jika ada yang sama maka akan kembali ke proses awal. Jika belum ada, sistem akan meminta password baru untuk pengguna baru, setelah itu sistem Proses perubahan password, melakukan scan id pengguna NFC Ring setelah itu masukan password yang lama kemudian masukkan password yang baru.

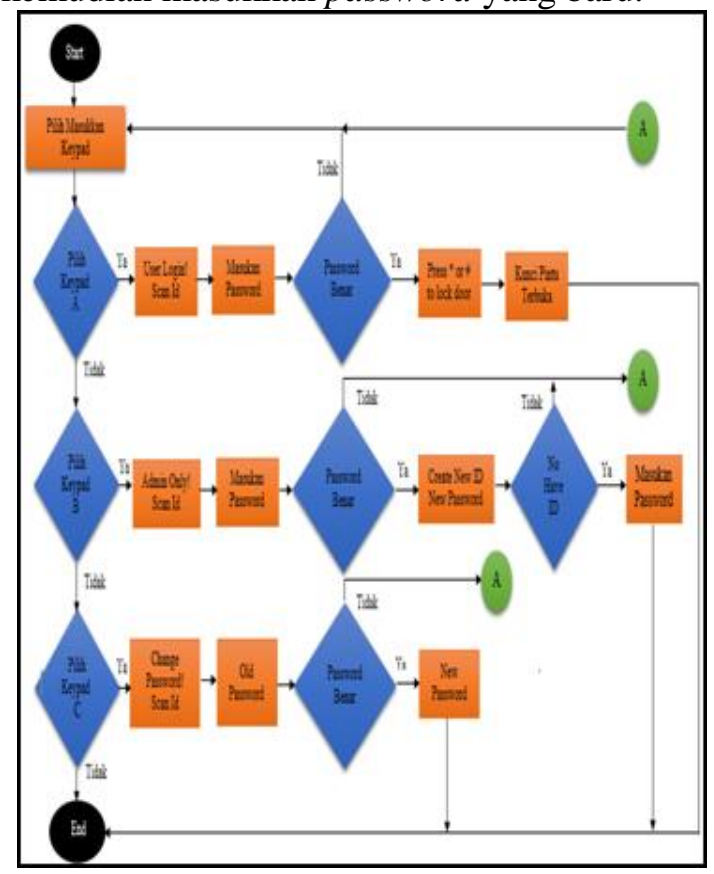

Gambar 14. Flowchart Perancangan Kunci Pintu 
G. Rancangan Perangkat Lunak IDE Arduino Mega 2560

Rancangan perangkat lunak menggunakan IDE Arduino mega 2560 adalah rancangan sistem program pada Arduino mega 2560 yang merupakan proses kerja untuk komponen agar sistem alat rancang dapat bekerja dengan baik dan juga EEPROM (Electrically Erasable Programmable Read Only Memory) sebagai tempat penyimpanan konfigurasi data pada alat rancang.

\section{H. Rancangan Wiring Digram Hardware Dan Software}

Gambar wiring diagram perangkat keras dan perangkat lunak yang telah di gabung menjadi rancangan alat yang akan digunakan sebagai perancangan kunci pintu menggunakan NFC ring dan password logger berbasis arduino mega 2560 seperti gambar 15.

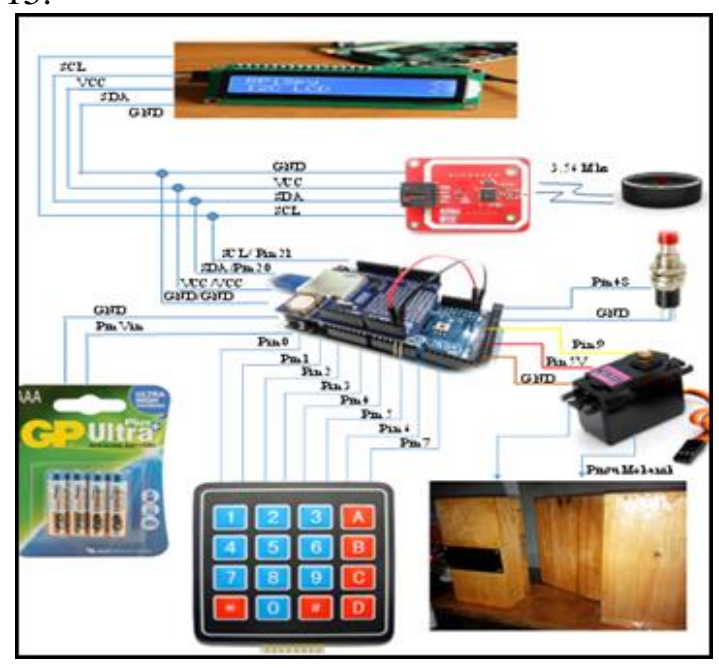

Gambar 15. Skematik Rancangan Keseluruhan

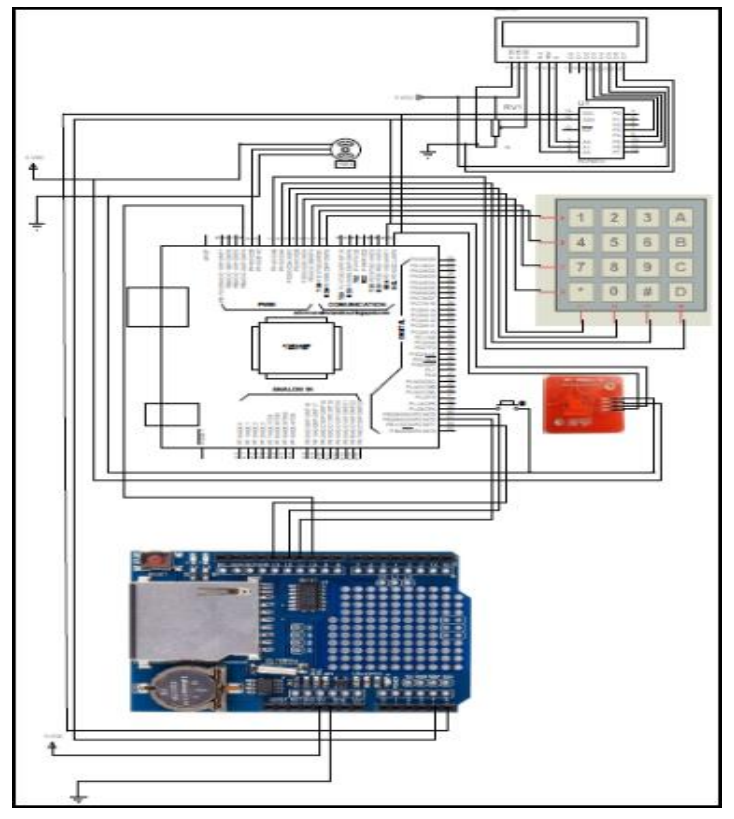

Gambar 16. Rancangan Wiring Diagram

\section{Metode Pengujian Dan Pengambilan Data}

Pengambilan data penelitian dilakukan dengan beberapa tahap pengujian yaitu:

1. Pengujian NFC Reader

Pengujian NFC Reader dilakukan dengan memperhatikan ada atau tidak data yang masuk saat NFC Ring melakukan komunikasi NFC ke NFC Reader dan password yang diterima oleh NFC Reader apakah sesuai dengan inputan dari NFC Ring. Pengujian ini dilakukan dengan serial monitor pada arduino mega 2560.

2. Pengujian pergerakan motor servo

Pengujian pergerakan motor servo dilakukan dengan memperhatikan arah gerak dari motor servo saat bergerak.

Adapun pengujian yang dapat dilakukan seperti nama, data uid1, data uid2 dan keterangan pergeralkan motor.

\section{HASIL DAN PEMBAHASAN}

\section{A. Analisis Dan Pengujian}

Pengujian NFC dilakukan pada 2 jenis NFC ring yang berbeda UID yaitu NFC ring, NFC name tag sebagai penggaanti NFC ring lainnya dan NFC card sebagai admin yang terdaftar pada arduino mega 2560 agar menjaga apabila password user lupa dan apabila NFC ring hilang, sedangkan NFC reader yang menggunakan protokol ISO14443A dalam menerima data dari NFC ring. 
Berikut bentuk protokol pada serial monitor ISO14443A pada PN532 NFC reader.

COM5 (Arduino/Ģenuino Mega or Mega 2560)

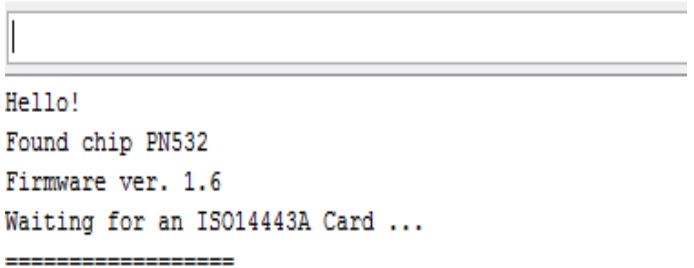

Gambar 17 Protokol Pada Serial Monitor

\section{B. Hasil Pengujian Data Pada NFC Ring}

Pengujian NFC Ring dilakukan pada 2 jenis NFC ring yang berbeda UID yaitu NFC ring R3F dan NFC ring beserta NFC card agar dapat mengenali UID NFC dapat dilihat pada serial monitor yang terdeteksi oleh NFC raeder dengan melakukan scan terhadap NFC reader, adapun datanya sebagai berikut:

1. Pengujian 1 pada Admin/NFC card, UID (46 1E 7A 00)Admin/NFC card memiliki UID yang tetap, tidak ada perubahan pada UID saat melakukan scan terhadap NFC Reader

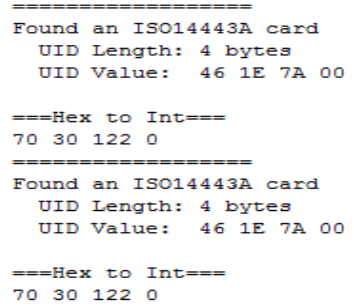

Gambar 18. Admin/NFC card, UID (46 1E 7A 00)

2. Pengujian 2 pada NFC ring $\mathrm{R} 3 \mathrm{~F}(B S)$, UID (04 5C F1 AA 4F 49 80) NFC ring black stone memiliki UID yang tetap, tidak ada perubahan pada UID saat melakukan scan terhadap NFC Reader.

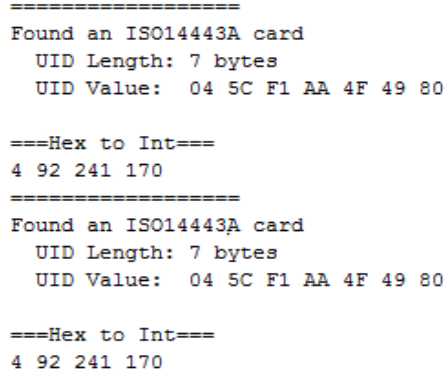

Gambar 19 NFC ring R3F (BS), UID (04 5C F1 AA 4F 49 80)
3. Pengujian 3 pada NFC R3F ring ( $R S)$, UID (04 85 E2 AA 4F 49 80)

NFC ring red stone memiliki UID yang tetap, sama seperti NFC ring black stone, tidak ada perubahan pada UID saat melakukan scan terhadap NFC Reader.

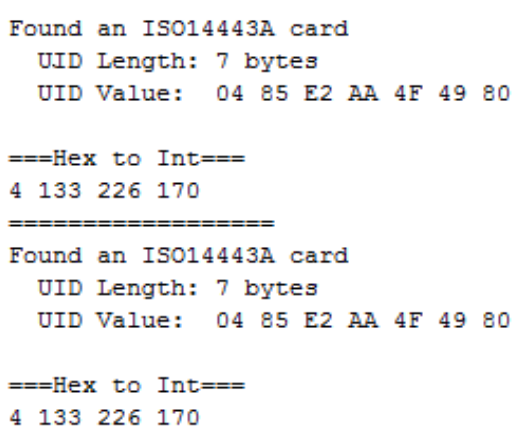

Gambar 20. NFC ring red stone, $\mathrm{UID}(0485$ E2 AA 4F 49 80)

4. Pengujian 4 pada NFC Ring R3, UID (04 88 84 9A 2C 49 81)

NFC name tag sebagai pengganti NFC ring lainnya, memiliki UID yang tetap, sama seperti NFC ring, tidak ada perubahan pada UID saat melakukan scan terhadap NFC Reader.

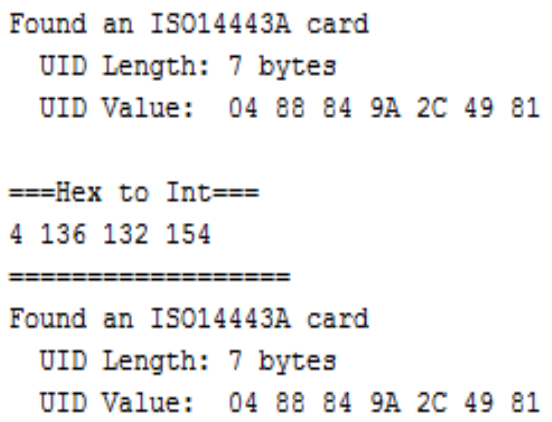

Gambar 21. NFC Ring R3, UID (04 88 84 9A 2C 49 81)

Berikut rangkuman dari pengujian yang telah dilakukan dari 4 pengetesan NFC ring dan NFC card sebagai admin dalam penelitian yang disusun dalam

Gambar Tabel 4.1: Tabel Rangkuman Pengujian Dalam Penelitian

Tabel 1.

Rangkuman Pengujian dalam Penelitian 


\begin{tabular}{|c|c|c|c|c|}
\hline No & Model NFC Ring & Data UID! & Data UID2 & Keterangan \\
\hline 1 & NFC CardAdmin & $(461 \mathrm{E} 7 \mathrm{~A} 00)$ & $(461 \mathrm{E} 7 \mathrm{~A} 00)$ & $\begin{array}{l}\text { Motor dalam } \\
\text { keadaan } \\
\text { terbouka }\end{array}$ \\
\hline 2 & NFCRingR3F(BS) & $\begin{array}{l}\text { (045CF1 AA4F } 49 \\
80)\end{array}$ & $\begin{array}{l}(045 C F 1 \mathrm{AA} \\
\text { 4F 4980) }\end{array}$ & $\begin{array}{l}\text { Motor dalam } \\
\text { keadaan } \\
\text { terbuka }\end{array}$ \\
\hline 3 & NFCRingR3F(RS) & $\begin{array}{l}(0485 \text { E2 AA4F } 49 \\
80)\end{array}$ & $\begin{array}{l}(0485 \mathrm{E} 2 \mathrm{AA} \\
4 \mathrm{~F} 4980)\end{array}$ & $\begin{array}{l}\text { Motor dalam } \\
\text { keadaan } \\
\text { terbuka }\end{array}$ \\
\hline 4 & NFCRingR3 & $\begin{array}{l}(0488849 A 2 C 49 \\
81)\end{array}$ & $\begin{array}{l}\text { (0488849A2C } \\
4981)\end{array}$ & $\begin{array}{l}\text { Motor dalam } \\
\text { keadaan } \\
\text { terbuka }\end{array}$ \\
\hline
\end{tabular}

Dari hasil penegujian data yang terdapat diatas NFC ring seri R3F dan R3 memiliki UID yang berbeda dan juga NFC card memiliki UID yang berbeda. NFC Reader dapat mengenali mmasing-masing perangkat sehingga mengakibatkan kunci pintu dapat terbuka karena memiliki UID yang tetap tidak berubah-ubah, kunci pintupun dapat terbuka dan sistem menyatakan bahwa perangkat sudah terdaftar pada perangkat yang belum pernah terdaftar kedalam sistem.

\section{Pengujian Pada Proses Data Logger}

Proses pengujian ini dalam bentuk notepad dan data logger yang dilakukan terhadap proses program arduino yang menyimpan program dalam EEFROM dan merekam aktifitas ke dalam data logger berupa waktu, tanggal, data dan aktifitas user dalam membuka kunci pintu sebagai berikut:
1] LOGIN - Notepad

File Edit Format View Help

16:32:54 23/6/2017 ==== Locked / Reset

16:33:01 $23 / 6 / 2017====$ Locked / Reset

16:33:01 $23 / 6 / 2017====$ Locked / Reset

$16: 33: 1823 / 6 / 2017===461 \mathrm{E} 7 \mathrm{~A} \theta$ has Log In

$16: 33: 22 \quad 23 / 6 / 2017====$ Unlocked

16:34:07 23/6/2017 $====$ Locked / Reset

16:34:28 23/6/2017 $====$ Locked / Reset

$16: 34: 43 \quad 23 / 6 / 2017====$ Unlocked

$16: 34: 48 \quad 23 / 6 / 2017====$ Locked / Reset

$16: 34: 56 \quad 23 / 6 / 2017====$ Unlocked

16:34:59 23/6/2017 ==== Locked / Reset

$16: 40: 16 \quad 23 / 6 / 2017====$ Locked / Reset

16:40:17 23/6/2017 $====$ Unlocked

$16: 40: 26 \quad 23 / 6 / 2017====$ Locked / Reset

17:13:22 23/6/2017 $====$ Locked / Reset

$17: 23: 5823 / 6 / 2017====$ Locked / Reset

$17: 23: 58 \quad 23 / 6 / 2017====$ Locked / Reset

$17: 24: 13 \quad 23 / 6 / 2017====$ Locked $/$ Reset
$17: 24: 2 \theta \quad 23 / 6 / 2017===46$ 1E $7 \mathrm{~A} \theta$ has Log In

$\begin{array}{ll}17: 24: 20 & 23 / 6 / 2017===4 \\ 17: 24: 22 & 23 / 6 / 2017====\text { Unlocked }\end{array}$

$17: 24: 22 \quad 23 / 6 / 2017====$ Unlocked
$17: 24: 27 \quad 23 / 6 / 2017===$ Locked / Reset

$17: 24: 27 \quad 23 / 6 / 2017====$ Locked / Reset
$17: 24: 41 \quad 23 / 6 / 2017====$ F5 4F CF 65 has Sign Up

$17: 24: 44 \quad 23 / 6 / 2017====$ F5 $4 F$ CF 65 has Log In

$17: 24: 45 \quad 23 / 6 / 2017====$ Unlocked

$17: 24: 49$ 23/6/2017 ==== Locked / Reset

17:24:57 23/6/2017 $====$ Locked / Reset

$17: 25: 13 \quad 23 / 6 / 2017===485$ E2 AA has Sign Up

$17: 25: 1523 / 6 / 2017===485$ E2 AA has Log In

$17: 25: 18 \quad 23 / 6 / 2017====$ Unlocked

17:25:21 23/6/2017 $====$ Locked / Reset

$17: 25: 35 \quad 23 / 6 / 2017===4$ SC F1 AA has Sign Up

$17: 25: 3723 / 6 / 2017===45 \mathrm{C}$ F1 AA has Log In

$17: 25: 39 \quad 23 / 6 / 2017====$ Unlocked

$17: 25: 43 \quad 23 / 6 / 2017====$ Locked / Reset

$17: 25: 5023 / 6 / 2017====$ Locked / Reset

23:32:43 $2 / 7 / 2017====$ Locked / Reset

23:32:46 $2 / 7 / 2017====$ Unlocked

Gambar 21. Pengujian data logger dalam bentuk notepad

\section{KESIMPULAN DAN SARAN}

\section{A. Kesimpulan}

Penelitian yang telah dilakukan serta hasil dari sistem kerja yang baik dapat juga diambil beberapa rangkuman kesimpulan sebagai berikut:

1. Merancang kunci pintu dengan menggunakan NFC ring (Near Field Communication) yang memiliki UID (Uniqe Identitas data) yang tetap dengan nilai frekuensi yang maksimal $13.56 \mathrm{MHz}$ sehingga NFC reader dapat mengenali ID NFC ring dengan baik serta keamanan password logger yang ditentukan user agar tingkat keamanan akan lebih baik sehingga pintu dapat terbuka dan agar terhindar dari pihak yang tidak dikenal.

2. NFC reader memiliki modul pemancar PN532 yang menangani komunikasi contactless di 13, $56 \mathrm{MHz}$ yang memiliki komunikasi serial I2C pada port digital memprogram agar dapat mengenali UID pada NFC ring dan address untuk penampilan pada LCD 16X2

3. Perancangan perangkat penelitian menggunakan data logger yang memiliki 
SD modul dan RTC (real time clock) sebagai modul penyimpanan untuk menyimpan data seperti merekam data, menciptakan jam, cap waktu, dan timer alarm, dll agar user dapat melihat semua aktifitas yang dilakukan dalam membuka kunci pintu oleh user ataupun dari pihak yang tidak dikenal dalam membuka kunci pintu.

\section{B. Saran}

Saran yang dapat peneliti berikan untuk dapat dilihat dalam perbaikan dan juga pengembangan untuk perubahan yang lebih baik dilakukan kedepaannya sebagai berikut:

1. Dapat di kembangkan dalam sistem keamanan dengan menggunakan alarm agar dapat mengetahui informasi keamanan apabila terjadi pembobolan pada kunci pintu dan dapat terintegrasi terhadap smartphone apabila terjadi pembobolan, user mendapatkan informasi dari smartphone.

2. Perancangan kunci pintu, perangkat keras dan perangkat lunak agar dapat lebih compact seperti pintu yang sebenarnya karena alat perancangan masih dalam bentuk prototype.

\section{DAFTAR PUSTAKA}

[1] NFC. Security, (online), (http://www.nearfieldcommunication.or g/nfc- security.html, diakses 30 Mei 2016)

[2] Ernst Haselsteiner and Klemens Breitfuß, "Security in Near Field Communication (NFC) Strengths and Weaknesses", Philips Semiconductors Mikronweg 1, 8101 Gratkorn, Austria

[3] Collin Mulliner, "Vulnerability Analysis and Attacks on NFC-enables Mobile Phones" International Conference on Availability, Reliability and Security, 2009

[4] Near Fiel Communication https://www.scribd.com/document/5167 7516/NFC

[5] NFC. Security, (online), (http://www.nearfieldcommunication.or $\mathrm{g} / \mathrm{nfc}$-security.html, diakses $30 \mathrm{Mei}$ 2016)
[6] Maulidar, Septian Rizky. "Smart Car Parking System pada Apartemen menggunakan Teknologi Near Field Communication (NFC)" Tugas Akhir, Universitas Widyatama, Bandung, 2014

[7] Jackom R3 http://www.jakcom.com/ins/R3/JAKCO M_R3.html

[8] Heri Adrianto Aan Darmawan "Arduino belajar cepat dan pemogramman".

[9] Motor Servo. Tower MG996, (online),(http://www.electronicoscaldas. com/datasheet/MG996_Tower-Pro.pdf

[10] https://cdnlearn.adafruit.com/downloads/pdf/adafr uit-data-logger-shield.pdf 